\title{
THE REFERENCE TO “A WORK OR SOFTWARE” AS THE FACTOR DETERMINING THE SCOPE OF THE EUROPEAN UNION PUBLIC LICENCE (EUPL) V. 1.2
}

by

KRZYSZTOF ŻOK*

Free and open source software (FOSS) has undoubtedly become an important element of intellectual property law. It is therefore not surprising that the European Commission developed its own non-proprietary licence, i.e. the European Union Public Licence (EUPL). The article examines the reference to 'a work of software' to determine the scope of the licence. For this purpose, the paper discusses the reasons for the creation of the EUPL, the relationship between a work and software as well as the structure of a computer program. The following considerations also include the compatible licences listed in the EUPL Appendix. The article concludes that the reference to a work or software is not accidental because it removes serious doubts arising from the concept of a computer program. Thus, this legal solution may facilitate the wider adoption of the licence.

\section{KEY WORDS}

Computer Program, Copyright Law, European Law, European Union Public Licence (EUPL), Non-proprietary Software Licences

krzysztof.zok@amu.edu.pl, Assistant Professor (Adjunct), Adam Mickiewicz University in Poznań, Faculty of Law and Administration, Poland. 


\section{INTRODUCTION}

\subsection{THE SIGNIFICANCE OF THE EUROPEAN UNION PUBLIC LICENCE (EUPL)}

On 20 October 2020, the European Commission adopted the new Open Source Software Strategy 2020-2034 'Think Open'. ${ }^{1}$ According to one of the governing principles provided for in the document, the Commission will share the source code of its future IT project, wherever it is reasonable. ${ }^{2}$ For this purpose, the European Union Public Licence (EUPL) v. 1.2 should be used as the preferred licence. ${ }^{3}$ This makes the EUPL particularly interesting, although there are other reasons for investigating it as well.

Firstly, non-proprietary licences often reflect the point of view of the legal systems of common law countries, especially the point of view of American law. ${ }^{4}$ This is the case, for example, with one of the most popular free and open source software (FOSS) licences, i.e. GNU General Public Licence (GPL), which has been identified as requiring internationalization. ${ }^{5}$ The general focus on American law is understandable, given that the Free Software Movement and the Open Source Software Movement started in the United States. ${ }^{6}$ Moreover, many IT companies are still located in the United States. The EUPL does not question the relevance or the usefulness of such non-proprietary licences. Indeed, its Appendix shows recognition, not negation, of some of the most popular FOSS licences developed in the United States. Instead, the EUPL offers the opportunity to take greater account of the European law perspective, which includes

1 Communication of 21 October 2020 'Open Source Software Strategy 2020-2023. Think Open'. $\quad \operatorname{COM}(2020) \quad 7149$ final. $\quad$ Available from: https://ec.europa.eu/info/sites/info/files/en_ec_open_source_strategy_2020-2023.pdf [Accessed 22 July 2021].

2 Op. cit., p. 9.

3 Commission Implementing Decision (EU) 2017/863 of 18 May 2017 updating the open source software licence EUPL to further facilitate the sharing and reuse of software developed by public administrations. Official Journal of the European Union (2017/L-128/59) 19 May. Available from: https://eur-lex.europa.eu/eli/dec_impl/2017/863/oj [Accessed 22 July 2021].

4 Dusollier, S. (2007) Sharing Access to Intellectual Property Through Private Ordering. Chicago-Kent Law Review, 82(3), p. 1427-1428.

5 Gomulkiewicz, R.W. (2005) General Public License 3.0: Hacking the Free Software Movement's Constitution. Houston Law Review, 42(4), pp. 1034-1035.

6 See Dusollier, S. (2007) Sharing Access to Intellectual Property Through Private Ordering. Chicago-Kent Law Review, 82(3), p. 1398-1399; González de Alaiza Cardona, J.J. (2007) Open Source, Free Software, and Contractual Issues. Texas Intellectual Property Law Review, 15(2), pp. 165-169, 178-179; Unni, V.K. (2016) Fifty Years of Open Source Movement: an Analysis through the Prism of Copyright Law. Southern Illinois University Law Journal, 40(2), pp. 279283. 
solutions characteristic of the legal systems belonging to the civil law tradition. ${ }^{7}$

Secondly, non-proprietary licences are mostly written in English as the only official language of the agreement. ${ }^{8}$ For instance, the Free Software Foundation, one of the major FOSS organizations, offers licences in English. ${ }^{9}$ Other language versions are available as non-binding information. This creates a potential barrier for those who prefer to use their national language. It should be noted that licence intelligibility can be a decisive factor for a software developer or a company interested in FOSS. Besides, a clear wording of the licence is essential due to the potential gap between the formal language in which typical licences are drawn up and the informal language used in FOSS communities. ${ }^{10}$ Moreover, Member States often oblige public organizations to use the local language. ${ }^{11}$ As a result, there was a need for a licence which would be useful in all official languages of the European Union. ${ }^{12}$ The EUPL uniquely addresses this issue, i.e. by offering multiple linguistic versions which have identical value. $^{13}$ This corresponds to the principle of linguistic diversity of the European Union, laid down in the Charter of Fundamental Rights of the European Union. ${ }^{14}$

7 Dusollier, S. (2007) Sharing Access to Intellectual Property Through Private Ordering. Chicago-Kent Law Review, 82(3), p. 1430; Schmitz, P.-E. (2013) the European Union Public Licence (EUPL). International Free and Open Source Software Law Review, 5(2), p. 125; Schmitz, P.-E. (2014) EUPL v.1.1. European Union Public Licence. Guides for Users and Developers. Available from: https://joinup.ec.europa.eu/collection/eupl/guidelines-users-and-developers [Accessed 22 July 2021], p. 4. Similarly, Schmitz, P.-E. (2013) the European Union Public Licence (EUPL). International Free and Open Source Software Law Review, 5(2), p. 122.

8 Dusollier, S. (2007) Sharing Access to Intellectual Property Through Private Ordering. Chicago-Kent Law Review, 82(3), p. 1428-1429.

9 Free Software Foundation. (2021) Licenses. [online]. Available from: https://www.gnu.org/licenses/licenses.html.en [Accessed 22 July 2021].

10 Villa, L. (2010) Lawyers in the Bazaar: Challenges and Opportunities for Open Source Legal Communities. International Free and Open Source Software Law Review, 2(1), p. 81-82.

11 Schmitz, P.-E. (2013) the European Union Public Licence (EUPL). International Free and Open Source Software Law Review, 5(2), p. 122.

12 Ibid.; Schmitz, P.-E. (2014) EUPL v.1.1. European Union Public Licence. Guides for Users and Developers. Available from: https://joinup.ec.europa.eu/collection/eupl/guidelines-usersand-developers [Accessed 22 July 2021], p. 4.

13 EUPL, Article 13. Multilingualism of the EUPL is considered its distinctive feature, see Schmitz, P.-E. (2013) the European Union Public Licence (EUPL). International Free and Open Source Software Law Review, 5(2), pp. 121 and 125; Wiebe, A. and Heidinger, R. (2009) European Union Public Licence - EUPL v. 1.1. [online]. Available from: https://joinup.ec.europa.eu/collection/eupl/documentation-directory-articles-eupl [Accessed 22 July 2021], p. 3. 
Thirdly, the multiplicity of non-proprietary licences is often considered a source of practical concerns about their compatibility. ${ }^{15}$ In particular, the question may arise to what extent it is possible to distribute an original computer program under one licence and its modifications or components (e.g. libraries) under another licence. The EUPL aims to remove this doubt by providing the following list of compatible licences (hereinafter: 'the compatible licences'):

- CeCILL v. 2.0 $0^{16}$ and v. 2.17\%

- Creative Commons Attribution-ShareAlike Unported v. 3.0 $(\mathrm{CCPL})^{18}$;

- $\quad$ Eclipse Public License (EPL) v. 1.019;

- $\quad$ European Union Public Licence (EUPL) v. 1.120 and 1.2;

- $\quad$ GNU Affero General Public License (AGPL) v. 3.021;

- $\quad$ GNU General Public License (GPL) v. 2.022 and v. 3.023,

- $\quad$ GNU Lesser General Public License (LGPL) v. 2.124 and v. 3.025;

14 Charter of Fundamental Rights of the European Union. Official Journal of the European Union (2012/C-326/391) 26 October. Available from: http://data.europa.eu/eli/treaty/char_2012/oj [Accessed 22 July 2021], Article 22.

15 Dusollier, S. (2007) Sharing Access to Intellectual Property Through Private Ordering. Chicago-Kent Law Review, 82(3), p. 1430; Schmitz, P.-E. (2013) the European Union Public Licence (EUPL). International Free and Open Source Software Law Review, 5(2), p. 123.

16 Commissariat à l'Energie Atomique, Centre National de la Recherche Sceintifique, Institut National de la Recherche en Informatique et en Automatique. (2006) CeCILL Free Software License Agreement. [online]. Available from: https://cecill.info/licences/Licence_CeCILL_V2en.html [Accessed 22 July 2021].

17 Commissariat à l'Energies Alternatives, Centre National de la Recherche Sceintifique, Institut National de la Recherche en Informatique et en Automatique. (2013) CeCILL Free Software License Agreement. [online]. Available from: https://cecill.info/licences/Licence_CeCILL_V2.1-en.html [Accessed 22 July 2021].

18 Creative Commons Corporation. Creative Commons Attribution-ShareAlike v. 3.0 Unported. [online]. Available from: https://creativecommons.org/licenses/by-sa/3.0/legalcode [Accessed 22 July 2021].

19 Eclipse Foundation. Eclipse Public License - v 1.0. [online]. Available from: https://www.eclipse.org/legal/epl-v10.html [Accessed 22 July 2021].

20 IDABC. (2009) European Union Public Licence - EUPL v.1.1. [online]. Available from https://wayback.archive-it.org/12090/20200212153832/https://ec.europa.eu/idabc/eupl.html [Accessed 22 July 2021].

${ }^{21}$ Free Software Foundation. (2007) GNU Affero General Public License. [online]. Available from: https://www.gnu.org/licenses/agpl-3.0.en.html [Accessed 22 July 2021].

22 Free Software Foundation. (1991) GNU General Public License, version 2. [online]. Available from: https://www.gnu.org/licenses/old-licenses/gpl-2.0.html [Accessed 22 July 2021].

23 Free Software Foundation. (2007) GNU General Public Licence. [online]. Available from: https://www.gnu.org/licenses/gpl-3.0.html [Accessed 22 July 2021].

24 Free Software Foundation. (1999) GNU Lesser General Public License, version 2.1. [online]. Available from: https://www.gnu.org/licenses/old-licenses/lgpl-2.1.html [Accessed 22 July 2021].

25 Free Software Foundation. (2007) GNU Lesser General Public License. [online]. Available from: https://www.gnu.org/licenses/lgpl-3.0.en.html [Accessed 22 July 2021]. 
- $\quad$ Mozilla Public Licence (MPL) v. 2.026;

- $\quad$ Open Source License (OSL) v. $2.1^{27}$ and v. 3.028;

- $\quad$ Québec Free and Open-Source Licence Reciprocity (LiLiQ-R) ${ }^{29}$;

- Québec Free and Open-Source Licence Strong Reciprocity (LiLiQ$\mathrm{R}+)^{30}$.

The EUPL lists several versions of the same compatible licence. This is understandable considering that newer versions do not automatically replace older versions. The licensor may thus still use a previous version of the licence. However, for the sake of brevity, the article indicates in the body text the version number of the licence where it is relevant to the argument. Otherwise, the version number is only displayed in the footnotes.

\subsection{THE SCOPE OF THE ARTICLE}

The analysis of FOSS licences often focuses on the rights and obligations of the parties. Such a perspective is justified and it certainly has practical significance. This article, however, aims to explore a different area, i.e. the subject matter covered by the licence. While the above issue has attracted less scholars' attention, it is not inconsequential. It should be noted that the EUPL is primarily directed to EU agencies. Nevertheless, it can also serve as a model licence for others interested in FOSS. ${ }^{31}$ Indeed, according to the data on the Joinup, a platform established by the European Commission, by the end of 2015 about 15.000 projects were distributed under the EUPL. ${ }^{32}$ From this point of view, the subject matter covered by the licence is essential since it determines the scope of application

26 Mozilla Foundation. Mozilla Public License Version 2.0. [online]. Available from: https://www.mozilla.org/en-US/MPL/2.0/ [Accessed 22 July 2021].

27 Open Source Initiative. (2004) the Open Software License 2.1 (OSL-2.1). [online]. Available from: https://opensource.org/licenses/osl-2.1.php [Accessed 22 July 2021].

28 Open Source Initiative. (2005) the Open Software License 3.0 (OSL-3.0). [online]. Available from: https://opensource.org/licenses/OSL-3.0 [Accessed 22 July 2021].

29 Québec - Forge gourvenementale. (2019) Québec Free and Open-Source Licence version 1.0 Reciprocity. [online]. Available from: https://forge.gouv.qc.ca/licence/en/liliq-v1-0/ [Accessed 22 July 2021]; Québec - Forge gourvenementale. (2019) Québec Free and Open-Source Licence version 1.1 - Reciprocity. [online]. Available from: https://forge.gouv.qc.ca/licence/en/liliq-v11/ [Accessed 22 July 2021].

30 Québec - Forge gourvenementale. (2019) Québec Free and Open-Source Licence version 1.0 Strong Reciprocity. [online]. Available from: https://forge.gouv.qc.ca/licence/en/liliq-v1-0 [Accessed 22 July 2021]; Québec - Forge gourvenementale. (2019) Québec Free and OpenSource Licence version 1.1 - Strong Reciprocity. [online]. Available from: https://forge.gouv.qc.ca/licence/en/liliq-v1-1/ [Accessed 22 July 2021].

31 Schmitz, P.-E. (2014) EUPL v.1.1. European Union Public Licence. Guides for Users and Developers. Available from: https://joinup.ec.europa.eu/collection/eupl/guidelines-usersand-developers [Accessed 22 July 2021], p. 4. 
of the EUPL. This in turn potentially impacts the popularity of the licence. Furthermore, the rights and obligations of the parties relate to the subject matter. Its inadequate description may thus impede the use, modification or distribution of the licensed computer program.

According to the preamble, the EUPL v. 1.2 applies to 'the Work'. ${ }^{33}$ This term is defined as 'the Original Work and its Derivative Works'. ${ }^{34}$ The licence explains these expressions by indicating that they refer to 'a work or software'. ${ }^{35}$ Interestingly, this description of the covered subject matter is sometimes regarded as an improvement over the EUPL v. 1.1. The latter licence applies to 'the Work or Software', which some scholars have found confusing. ${ }^{36}$ In my opinion, however, the above comment requires a more detailed analysis. Despite the different wording of the preamble, the EUPL v. 1.2 still refers to 'a work or software'. Nevertheless, it should be noted that the previous version of the licence defines the terms 'the Original Work' and 'the Software' as software only. There is no reference to a work as the denotation. Hence, the EUPL v. 1.2 seems to adopt a broader scope of application, which is not necessarily clearer or more useful.

The article focuses on the examination of the concept of a 'work' or 'software' as the basis for determining the subject matter covered by the EUPL. Additionally, the paper considers the compatible licences to fill in the gaps which result from not clarifying what constitutes a work or software under the licence. This approach also makes it possible to reflect on the consistency of the EUPL as well as the advantages and disadvantages of the licence. Finally, it should be emphasized that the article does not analyse the question of the originality of a computer program as well as the question of derivative works. It would certainly be beyond the scope of this paper to consider these issues because of their complexity in the context of FOSS.

\section{WORK AS THE COVERED SUBJECT MATTER}

\footnotetext{
32 Joinup. Impact of the EUPL. [online]. Available from: https://joinup.ec.europa.eu/collection/eupl/impact-eupl [Accessed 22 July 2021].

33 EUPL v. 1.2, preamble.

34 EUPL v. 1.2, Article 1.

35 Ibidem.

36 Schmitz, P.-E. (2013) the European Union Public Licence (EUPL). International Free and Open Source Software Law Review, 5(2), p. 126. See EUPL v. 1.1, preamble.
} 
As in the previous version, the EUPL v. 1.2 does not define the term 'work'. However, it is worth noting that under the EUPL v. 1.1 some scholars treated this expression as a reference to the subject matter covered by copyright. ${ }^{37}$ Others regarded the term 'work' as a synonym for 'software and/or documentation'. ${ }^{38}$ In my opinion, the first position is correct and should also be adopted under the current version of the licence. The definition of 'the Original Work' in the EUPL v. 1.2 implies two different subject matters and thus precludes the term 'work' from being restricted to software only. ${ }^{39}$ Otherwise, part of this provision would be redundant, which is difficult to accept. Instead, the discussed expression should be understood as the subject matter covered by copyright. ${ }^{40}$ Besides, the other language versions of the EUPL v. 1.2 support this conclusion. For example, the French and German texts of the licence use in this context standard legal terminology for copyrighted material ('ouvre' and 'Werk' respectively). ${ }^{41}$

The above conclusion does not fully eliminate the uncertainty about the subject matter covered by the licence. Pursuant to Software Directive, computer programs are protected by copyright as literary works within the meaning of the Berne Convention. ${ }^{42}$ Thereby, software also constitutes a work. More importantly, this classification is not only limited to European law. Rather, it can be seen as the international legal standard. For instance, the Treaty on Trade-Related Aspects of Intellectual Property (TRIPS) provides for that computer programs should be protected by copyright as literary works under the Berne Convention. ${ }^{43}$ Consequently, the question

${ }_{37}$ Wiebe, A. and Heidinger, R. (2009) European Union Public Licence - EUPL v. 1.1. [online]. Available from: https://joinup.ec.europa.eu/collection/eupl/documentation-directoryarticles-eupl [Accessed 22 July 2021], p. 6.

38 Schmitz, P.-E. (2014) EUPL v.1.1. European Union Public Licence. Guides for Users and Developers. Available from: https://joinup.ec.europa.eu/collection/eupl/guidelines-usersand-developers [Accessed 22 July 2021], p. 7.

39 EUPL v. 1.2, Article 1.

40 Schmitz, P.-E. (2013) the European Union Public Licence (EUPL). International Free and Open Source Software Law Review, 5(2), p. 126.

41 EUPL v. 1.2, preamble and Article 1 (the French and German texts).

42 Berne Convention for the Protection of Literary and Artistic Works, 9 September 1886 (as amended on 28 September 1979). Available from: https://wipolex.wipo.int/en/treaties/textdetails/12214 [Accessed 22 July 2021] (hereinafter: 'Berne Convention'); Directive 2009/24/EC of the European Parliament and of the Council of 23 April 2009 on the legal protection of computer programs (Codified version). Official Journal of the European Union (2009/L-111/16) 5 May. Available from: http://data.europa.eu/eli/dir/2009/24/oj [Accessed 22 July 2021] (hereinafter: 'Software Directive'), Article 1(1). 
arises why the EUPL refers to the general concept of work when it also covers a specific type of work, i.e. software.

Moreover, the European Commission clearly stated that the main purpose of the EUPL is to 'further facilitate the sharing and reuse of software developed by public administrations' ${ }^{44}$. Therefore, the licence seems to be specifically intended for computer programs. The conclusion is in line with the fact that non-proprietary licences were initially developed for computer programs and are still often associated with them. Yet, the EUPL Appendix clarifies that the CCPL applies 'for works other than software ${ }^{45}$. The EUPL thus appears to implicitly accept its broader scope. This makes the reference to a work as a way of describing the subject matter covered by the EUPL even more puzzling.

However, a similar solution can be found in some of the compatible licences. $^{46}$ Under the GPL v. 2.0, some scholars pointed out that the definition of a computer program goes beyond its literal meaning and includes other works such as a novel or a piece of music. ${ }^{47}$ Yet, they also added that the licence mainly covers software. In my view, the acceptance of the broad scope of the GPL is correct and it corresponds with the position of the Free Software Foundation. ${ }^{48}$ Nevertheless, the compatible licences are usually only analysed from the perspective of software. The term 'work' is then identified with a computer program (e.g. a software library). ${ }^{49}$

It should also be emphasized that referring to a work is not a uniform approach. Other compatible licences indicate that they apply to a computer

43 Marrakesh Agreement Establishing the World Trade Organization - Annex 1C. Agreement on Trade-Related Aspects of Intellectual Property Rights, 15 April 1994. Available from: https://www.wto.org/english/docs_e/legal_e/27-trips_01_e.htm [Accessed 22 July 2021], Article 10.

44 Commission Implementing Decision (EU) 2017/863 of 18 May 2017 updating the open source software licence EUPL to further facilitate the sharing and reuse of software developed by public administrations. Official Journal of the European Union (2017/L-128/59) 19 May. Available from: https://eur-lex.europa.eu/eli/dec_impl/2017/863/oj [Accessed 22 July 2021], recital 4.

45 EUPL v. 1.2, Appendix.

46 AGPL, preamble; GPL v. 2.0, Article 0; GPL 3.0, preamble. Similarly, LiLiQ-R v. 1.0, Articles 1 and 2; LiLiQ-R+ v. 1.0, Articles 1 and 2; LiLiQ-R v. 1.1, Articles 1 and 2; LiLiQ-R+ v. 1.1, Articles 1 and 2. Moreover, according to the preamble of the LGPL v. 3.0, the licence incorporates the provisions of the GPL v. 3.0. As a result, both licences share the same scope.

47 Schultz, C. (2005) Ziffer 0. In: Die GPL kommenirt und erklärt. Köln: O’Reilly, p. 37.

48 Free Software Foundation. (2020) Frequently Asked Questions about the GNU Licenses. [online]. Available from: https://www.gnu.org/licenses/gpl-faq.html [Accessed 22 July 2021].

49 See Bain, M. (2010) Software Interactions and the GNU General Public License. International Free and Open Source Software Law Review, 2(2), pp. 172-173. 
program or software. ${ }^{50}$ More importantly, they do not state that they cover broadly understood works. Only two compatible licences define their scope by using the general concept of 'any original work of authorship' or 'literary and/or artistic work', without mentioning a computer program or software. ${ }^{51}$

From this perspective, it appears that the reference to a work or software in the EUPL is not accidental. Otherwise, it could be expected that the revised version of the licence would remove the confusing reference to a work. This, in turn, raises the question of the reasons for adopting such a solution. In particular, it could be argued that extending the scope of the EUPL is necessary or else the purpose of the licence could not be achieved. The verification of this assumption, however, requires showing that the limitation of the covered subject matter to computer programs only is not satisfactory.

\section{SOFTWARE AS THE COVERED SUBJECT MATTER}

\subsection{COMPUTER PROGRAM ACCORDING TO SOFTWARE DIRECTIVE}

The EUPL does not explain what constitutes software. Some of the compatible licences follow the same approach. ${ }^{52}$ However, most define the term 'computer program' or 'software', although it should be emphasized only a few of them provide a detailed explanation. They are discussed in the next subsection (see 3.2). The definitions in other compatible licences are based on a generalization (e.g. software is understood as a work) ${ }^{53}$ or a tautology (e.g. software is understood as a computer program $)^{54}$. As a result, they offer limited insight into the subject matter covered by the EUPL.

It is worth noting that proper understanding of software is not only a matter of theoretical dispute. The general purpose of the licence is to allow the licensee to undertake activities related to the work (e.g. a computer program) which would otherwise constitute an infringement of exclusive

50 CeCILL v. 2.0, preamble; CeCILL v. 2.1, preamble; EPL v. 1.0, preamble; LGPL v. 2.1, Article 0 ; MPL v. 2.0, Articles 1.3, 1.4 and 2.1.

51 CCPL v. 3.0, preamble, Article 1(h); OSL v. 2.1, preamble; OSL v. 3.0, preamble.

52 OSL v. 2.1, preamble; OSL v. 3.0, preamble.

53 AGPL v. 3.0, Article 0; GPL v. 2.0, Article 0; GPL v. 3.0, Article 0.

${ }^{54}$ CeCILL v. 2.0, Article 1; CeCILL v. 2.1, Article 1; EPL v. 1.0, Article 1; GPL v. 2.0, Article 0; LiLiQ-R v. 1.0, Article 2; LiLiQ-R+ v. 1.0, Article 2; LiLiQ-R v. 1.1, Article 2; LiLiQ-R+ v. 1.0, Article 2; MPL v. 2.0, Article 1.4. 
rights (i.e. copyright). Consequently, if an element of the work is not protected, it can be used freely, without the need to obtain the rightholder's authorization. This, in turn, raises the question of parts of the software that are covered by a licence.

The answer is not always easy since the exact scope of protection may differ from one legal system to another. ${ }^{55}$ Some of the compatible licences aim to solve this problem by choosing the applicable law ${ }^{56}$ or stipulating that their terms should be interpreted in accordance with specific legal acts. ${ }^{57}$ The EUPL adopts the first approach. In principle, the licence recognizes that parties are free to choose the applicable law. ${ }^{58}$ In the absence of such a choice, the EUPL is governed by the law of the Member State where the licensor has its seat, resides or has its registered office. If the latter requirement is not met, the licence is subject to Belgian law. Therefore, the EUPL is always governed by the law of one or another Member State, unless the parties decide otherwise.

The EUPL also stipulates that the disputes arising from its provisions should be heard by the Court of Justice of the European Union. ${ }^{59}$ Therefore, the Court can be expected to follow its own decisions based on Software Directive. This further strengthens the reference to European law, although express jurisdiction of the Court is limited to litigation between the European Union institutions, bodies, offices or agencies. Thus, the EUPL achieves one of its goals, effectively introducing the European perspective on software protection. Hence, in a typical situation other legal doctrines, e.g. Arbitration-Filtration-Comparison test which is often used in the United States, will probably have limited relevance. ${ }^{60}$

Moreover, the complex structure of computer programs can be another source of practical concerns. As provided for in Software Directive, the protection applies only to the expression of a computer program. ${ }^{61} \mathrm{It}$ does not extend to the ideas and principles underlying any element

\footnotetext{
55 Bain, M. (2010) Software Interactions and the GNU General Public License. International Free and Open Source Software Law Review, 2(2), pp. 170-171.

56 CeCILL v. 2.0, Article 13.1; CeCILL v. 2.1, Article 13.1; EPL v. 1.0, Article 7; LiLiQ-R v. 1.0, Article 11; LiLiQ-R v. 1.1, Article 11; LiLiQ-R+ v. 1.0, Article 11; LiLiQ-R+ v. 1.1, Article 11. OSL v. 2.1, Article 11; OSL v. 3.0, Article 11.

57 CCPL v. 3.0, Article 8(f).

58 EUPL, Article 15.

59 EUPL, Article 14.

60 Similarly, Bain, M. (2010) Software Interactions and the GNU General Public License. International Free and Open Source Software Law Review, 2(2), p. 169.

61 Software Directive, Article 1(2) and Recital 11.
} 
of the above type of work. This also refers to interfaces, i.e. parts of the computer program which enable the interconnection and interaction between elements of software and hardware. ${ }^{62}$ Furthermore, Software Directive classifies logic, algorithms and programming languages as unprotected ideas and principles. ${ }^{63}$ The Court of Justice of the European Union approved this conclusion in the SAS Institute Inc. case by stating that the functionality of a computer program as well as the programming language and the format of data files should not be treated as a form of expression of a computer program. ${ }^{64}$ While this decision does not directly apply to FOSS, it may have an impact on the linking of computer programs (e.g. application programming interfaces (APIs)). ${ }^{65}$

More importantly, in the Bezpečnostní softwarová asociace case, the Court of Justice of the European Union held that interfaces, in particular graphic user interfaces (GUI), are not a form of expression of a computer program. ${ }^{66}$ The Court put forward two arguments in support of its ruling. Firstly, the form of expression of a computer program should enable the reproduction of the software. This requirement is not met in the case of interfaces since they do not allow the user to copy the computer program. Secondly, interfaces are generally bound by their technical function. Therefore, a software developer who creates them often does not enjoy sufficient freedom of expression. As a result, interfaces do not meet the requirement of originality. However, an interface may be protected as a separate work under Directive 2011/29, if it constitutes its author's own intellectual creation. ${ }^{67}$ Hence, the audio and visual components of the software in a general sense are not parts of the computer program in the legal sense.

While the above decision is correct, it may be counter-intuitive to a layperson. In particular, it can be expected that an average user will identify graphic user interfaces and other on-screen displays with

62 Software Directive, Recital 10.

63 Software Directive, Recital 11.

${ }^{64}$ Judgment of 2 May 2012, SAS Institute Inc., C-406/10, EU:C:2012:259, paragraphs 39-46.

65 Schmitz, P.-E. (2013) the European Union Public Licence (EUPL). International Free and Open Source Software Law Review, 5(2), pp. 127-128.

${ }^{66}$ Judgment of 5 October 2009, Bezpečnostní softwarová asociace, C-393/09, EU:C:2010:816, paragraphs 28-42 and 49-51.

67 Directive 2001/29/EC of the European Parliament and of the Council of 22 May 2001 on the harmonisation of certain aspects of copyright and related rights in the information society. Official Journal of the European Communities (2001/L-167/10) 22 June. Available from: http://data.europa.eu/eli/dir/2001/29/oj [Accessed 22 July 2021]. 
the computer program itself. At the same time, these displays should not be considered irrelevant simply because they do not constitute a form of expression of software. On the contrary, they often impact the way the users experience the computer program. This, in turn, is a key factor which influences the popularity of the software. Limiting the scope of the EUPL to only computer programs could therefore be disadvantageous. This would introduce the uncertainty as to whether a specific part of the computer program can be treated as its form of expression. From this point of view, the reference to a work as a subject matter cover by the EUPL is justified. It removes these doubts and consequently allows the licensee to use the IT project as a whole, regardless of how its particular elements are classified.

The practical ramifications of the distinction between a work and software are evident in the case of a 'fork'. This term is used in FOSS communities to describe a situation in which an existing IT project is almost completely relaunched under a new leader. ${ }^{6}$ Forking may be justified by philosophical reasons (i.e. the initial IT project is overtaken by a proprietary licensor) or technical reasons (i.e. the leader of the initial IT project refuses to merge new functions or modify software). From a legal point of view, however, forking often requires copying not only the computer program in the strict sense but also its name, logo and other intangible assets. The latter elements are usually outside the concept of software. Thus, a narrow definition of the covered subject matter could prevent the effective reuse of software, which is one of the main objectives of the EUPL.

From this point of view, it could be argued that the EUPL should simply refer to the work, without explicitly mentioning software in its scope of application. After all, the licence would then also cover computer programs with all their relevant components as copyrighted materials. However, the question arises whether this approach does not dilute the concept of a computer program. In my opinion, a negative answer should be given in this respect. It should be noted that the concept of a computer program and the concept of a work are determined by European and Member States legislation and case law. The parties cannot thus contractually extend the copyright protection because this

68 Schmitz, P.-E. (2013) the European Union Public Licence (EUPL). International Free and Open Source Software Law Review, 5(2), p. 129. 
would violate the closed catalogue of rights in rem (i.e. rights effective against anyone). Consequently, the concept of a computer program as such should be defined, in particular, on the basis of Software Directive, irrespective of the scope of the EUPL. If the licence referred only to a work, the court and the parties would still need to consider the type of work covered by the licence and the extent of its protection.

This is probably the weakest side of the above approach. A simple reference to the work does not solve the problem of making the scope of the EUPL clear and operational. The approach only reformulates the doubts from a different perspective. Therefore, it could be argued that the reference to 'a work or software' is helpful since it shows possible legal frameworks governing the licensed subject matter. Moreover, the parties cannot contractually extend the copyright protection. However, they can specify which protected elements of the computer program are covered by the licence. Hence, the reference to software could contribute to a more precise definition of the scope of the EUPL, if the licence clearly indicated these elements.

\subsection{COMPUTER PROGRAM ACCORDING TO THE COMPATIBLE LICENCES}

Unlike the EUPL, several compatible licences, including the most popular ones, define at least some software components, thus offering a more detailed description of a computer program. Therefore, it could be argued that the definitions contribute to the success of these compatible licences. On the other hand, the lack of a similar explanation seems unfavourable for the EUPL. Especially when one considers that the compatible licences indicate the parts of a computer program which have not been identified in the European case law.

A comprehensive set of definitions is found in the AGPL v. 3.0 and the GPL v. 3.0 which explain many key terms ('Standard Interface', 'System Libraries', 'Major Component' and 'The Corresponding Source'). The purpose of this clarification is to make sure that the recipient of the computer program in the form of object code has also access to the complete source code. ${ }^{69}$ According to these licences, the conveying of non-source forms of software should be accompanied by the transfer

${ }^{69}$ AGPL v. 3.0, Article 1; GPL v. 3.0, Article 1. 
of the Corresponding Source. ${ }^{70}$ Similarly, the GPL v. 2.0 indicates that the complete source code covers 'all the source code for all modules it contains, plus any associated interface definition files, plus the scripts used to control compilation and installation of the executable ${ }^{\prime 71}$. Nevertheless, this does not refer to 'anything that is normally distributed (in either source or binary form) with the major components (compiler, kernel, and so on) of the operating system on which the executable runs, unless that component itself accompanies the executable $\mathrm{e}^{72}$.

A similar provision can also be found in the LGPL v. 2.1.73 More importantly, however, another set of definitions is provided for in the LGPL v. 2.1 ('library', 'Library' [sic], 'work that uses the Library' and 'work based on the Library') $)^{74}$ and the LGPL v. 3.0 ('The Library', 'Application', 'Combined Work', 'Minimal Corresponding Source' and 'Corresponding Application Code' $)^{75}$. The latter licence also refers to 'Library Header Files' and 'Combined Libraries'. ${ }^{76}$ The above definitions aim to address the uncertainty regarding the impact of using software libraries on the scope of these licences. It should be noted that linking a computer program to a library may create a derivative work. ${ }^{77}$

Moreover, it could be argued that distinguishing particular elements of a computer program is characteristic of free software licences which originated in the United States. This is, however, not correct. a similar solution can also be found in CeCILL which has been specially developed to meet the requirements of European (French) legislation. These licences introduce the concepts of 'Module', 'External Module' and 'Internal Module' ${ }^{78}$ The distinction is significant since CeCILL does not apply to External Modules which may be distributed under the license chosen

70 AGPL v. 3.0, Article 6; GPL v. 3.0, Article 6.

71 GPL v. 2.0, Article 3.

72 GPL v. 2.0, Article 3.

73 LGPL v. 2.1, Article 6.

74 LGPL v. 2.1, Article 0.

75 LGPL v. 3.0, Article 0.

76 LGPL v. 3.0, Articles 3 and 5, respectively.

77 See Bain, M. (2010) Software Interactions and the GNU General Public License. International Free and Open Source Software Law Review, 2(2), pp. 175-178; Dusollier, S. (2007) Sharing Access to Intellectual Property Through Private Ordering. Chicago-Kent Law Review, 82(3), pp. 1416-1418; Gue, Th. (2012) Triggering the Infection: Distribution and Derivative Works under the GNU General Public License. University of Illinois Journal of Law, Technology $\mathcal{E}$ Policy, 1, p. 129-139; Morgan, M.F. (2010) the Cathedral and the Bizarre: an Examination of the "Viral" Aspects of the GPL. John Marshall Journal of Computer and Information Law, 27(3), pp. 386-416 and 464-492.

78 CeCILL v. 2.1, Article 1; CeCILL v. 2.0, Article 1. 
by the licensee who created them. ${ }^{79}$ Incontrast, the EUPL does not specifically address any of the above issues.

From this point of view, the description of software as the subject matter covered by the EUPL is less precise than in some of the most popular compatible licences. As a result, the question of the completeness of source code, software libraries and supplementary functions and services is largely left with the parties and the courts. This may consequently hinder a wider adoption of the EUPL. However, it could also be argued that the lack of precision is a positive feature of the licence. The EUPL thus gains flexibility which is much needed in the rapidly changing area of IT law. Moreover, the use of general concepts may facilitate the adoption of the licence because it avoids the difficulties which could arise from the difference between the legal systems of the Member States. The increasing use of the EUPL suggests that the broad reference to the software may be satisfactory to the parties.

It is also worth noting that more wordy licences, particularly the GPL, has been criticized for lack of clarity ${ }^{80}$ For instance, despite the definitions, the completeness of the source code may still raise practical concerns. The GPL v. 3.0 illustrates this well:

"Iflor example, Corresponding Source includes interface definition files associated with source files for the work, and the source code for shared libraries and dynamically linked subprograms that the work is specifically designed to require, such as by intimate data communication or control flow between those subprograms and other parts of the work." ${ }^{11}$

As a result, it can be expected that an average user may find it difficult to understand these definitions since they raise doubts even among IT professionals. Therefore, the length of the licences does not translate into its intelligibility.

79 CeCILL v. 2.1, Article 5.3.3 and 6.3; CeCILL v. 2.0, Article 5.3.3 and 6.3.

80 Gomulkiewicz, R.W. (2005) General Public License 3.0: Hacking the Free Software Movement's Constitution. Houston Law Review, 42(4), p. 1035; Morgan, M.F. (2010) the Cathedral and the Bizarre: an Examination of the "Viral" Aspects of the GPL. John Marshall Journal of Computer and Information Law, 27(3), pp. 351-352.

${ }^{81}$ GPL v. 3.0, Article 1. 


\section{DOCUMENTATION}

Some of the compatible licences also treat documentation as part of software. ${ }^{82}$ The OSL even specifies that documentation should describe how to modify the computer program. $^{83}$ Yet, such a classification is considered rare among FOSS licences. ${ }^{84}$ For example, the Free Software Foundation recommends a separate licence made specifically for manuals. ${ }^{85}$ At first glance, the extension of the concept of software may seem irrelevant. However, a closer examination reveals serious legal doubts. In particular, the uncertainty arises whether documentation can be regarded as a protected element of a computer program within the meaning of Software Directive.

The importance of this question stems from the fact that documentation significantly facilitates understanding how a computer program works. This applies not only to FOSS but also to proprietary computer programs. As a result, the licensee is usually interested in obtaining the documentation. However, in the case of FOSS, documentation becomes almost essential. Such computer programs are often developed over an extended period by many people who do not directly interact with each other and who are not part of the same organization. As a result of this 'bazaar' method, it is crucial to get the most complete information about the software. ${ }^{86}$ In contrast, proprietary computer programs are frequently developed according to the 'cathedral' method. This term refers to a situation in which one entity coordinates the process of creating a computer program and thus has all the necessary information.

Nevertheless, the answer to the above question seems negative due to the difference between software and its documentation. Indeed, in the SAS Institute Inc. case, the Court of Justice of the European Union held that user manuals can be protected under Directive 2001/29. ${ }^{87}$ As a result, it can be

\footnotetext{
${ }^{82}$ CeCILL v. 2.0, Article 1; CeCILL v. 2.1, Article 1; EPL v. 1.0, Article 1(a); LiLiQ-R v. 1.0, Article 2; LiLiQ-R v. 1.1, Article 2; LiLiQ-R+ v. 1.0, Article 2; LiLiQ-R+ v. 1.1, Article 2.

83 OSL v. 2.1, Article 3; OSL v. 3.0, Article 3.

${ }^{84}$ Osborne, K. (2015) License Profile: the Eclipse Public License. International Free and Open Source Software Law Review, 7(1), p. 4.

85 Free Software Foundation. (2020) Frequently Asked Questions about the GNU Licenses. [online]. Available from: https://www.gnu.org/licenses/gpl-faq.html [Accessed 22 July 2021]. See Free Software Foundation. (2008) GNU Free Documentation License. Available from https://www.gnu.org/licenses/fdl-1.3.html [Accessed 22 July 2021].

86 Raymond, E.S. (2000) the Cathedral and the Bazaar. [online]. Available from: http://www.catb.org/ esr/writings/cathedral-bazaar/cathedral-bazaar/ [Accessed 22 July 2021].

87 Judgment of 2 May 2012, SAS Institute Inc., C-406/10, EU:C:2012:259, paragraphs 63-70.
} 
argued that books or files describing how a computer program works are excluded from the scope of Software Directive. Therefore, they do not fall within the concept of a computer program. This would once again point to the accuracy of the EUPL which refers not only to software but also to a work. Indeed, the conclusion is shared by some scholars. ${ }^{88}$ At the same time, the broad description of the covered subject matter seems to be better suited for the needs of FOSS. Namely, it could be argued that software developers can distribute not only a computer program (with all its relevant components) but also related documentation under a single licence.

Without questioning this conclusion, it is worth noting that the status of documentation under Software Directive is more complex. According to the Directive, the term 'computer program' includes 'preparatory design work leading to the development of a computer program provided that the nature of the preparatory work is such that a computer program can result from it at a later stage' 89 . The Court of Justice of the European Union also approved this definition. ${ }^{90}$ Moreover, it could be assumed that the significance of documentation in the context of FOSS may often translate into a precise description of the computer program. Hence, it cannot be ruled out that for this reason the documentation may be sufficiently complete for the reproduction of the software. The reference to a work in the EUPL could thus be seen as redundant since at least some of documentation would classify as a preparatory design work.

In my opinion, however, the above provision is not entirely without a doubt. The Swedish High Court requested a preliminary ruling which would determine how complete such materials should be to qualify as software. ${ }^{91}$ Unfortunately, the question was withdrawn and the Court of Justice of the European Law could not answer it. Therefore, the reference to a work in the EUPL seems a better solution as it avoids the uncertainty related to the completeness of documentation.

88 Schmitz, P.-E. (2013) the European Union Public Licence (EUPL). International Free and Open Source Software Law Review, 5(2), p. 126. Under the EUPL v. 1.1, see Wiebe, A. and Heidinger, R. (2009) European Union Public Licence - EUPL v. 1.1. [online]. Available from: https://joinup.ec.europa.eu/collection/eupl/documentation-directory-articles-eupl [Accessed 22 July 2021], p. 6.

89 Software Directive, Recital 7 and Article 1(1).

90 Judgment of 5 October 2009, Bezpečnostní softwarová asociace, C-393/09, EU:C:2010:816, paragraph 37; Judgment of 2 May 2012, SAS Institute Inc., C-406/10, EU:C:2012:259, paragraph 37.

91 Request of 9 May 2018, Dacom Limited v IPM Informed Portfolio Management AB, C-313/18, Official Journal of European Union (2018/C-268/31) 30 July. Available from: https://eurlex.europa.eu/legal-content/EN/TXT/?uri=CELEX\%3A62018CN0313 [Accessed 22 July 2021]. 


\section{SUMMARY}

The EUPL is an interesting legal solution aimed at creating a European non-proprietary licence. For this purpose, the licence is governed by the law of one of the Member States. As a result, the harmonized legal framework of Software Directive applies to the EUPL. Moreover, the licence is available in all the official languages of the European Union.

The article analyses the reference to 'a work or software' which defines the scope of the licence. The expression may seem puzzling since a computer program is a type of work. However, a closer examination shows that a reference only to the software would be unsatisfactory. The parties would then suffer the consequences of an incorrect assessment of what constitutes software. This could easily raise practical concerns due to the complex structure of computer programs. The reference to the broader concept of work reduces these doubts by including under the EUPL the components which are not protected as software. It also provides greater flexibility, much needed in the rapidly changing area of IT law. Besides, the generality of the EUPL facilitates seamless integration with the compatible licences.

The article also indicates that some of the compatible licences offer a more precise definition of software. The parties could probably benefit from the adoption of a similar solution in the EUPL. Nevertheless, the article shows that such definitions are not necessary for the proper functioning of the licence in question.

\section{LIST OF REFERENCES}

[1] Bain, M. (2010) Software Interactions and the GNU General Public License. International Free and Open Source Software Law Review, 2(2).

[2] Berne Convention for the Protection of Literary and Artistic Works, 9 September 1886 (as amended on 28 September 1979). Available from: https://wipolex.wipo.int/en/treaties/textdetails/12214 [Accessed 22 July 2021].

[3] Charter of Fundamental Rights of the European Union. Official Journal of the European Union (2012/C-326/391) 26 October. Available from: http://data.europa.eu/eli/treaty/char_2012/oj [Accessed 22 July 2021].

[4] Christensen, T.M. (2006) the GNU General Public License: Constitutional Subversion? Hastings Constitutional Law Quarterly, 33(4).

[5] Commissariat à l'Energie Atomique, Centre National de la Recherche Sceintifique, 
Institut National de la Recherche en Informatique et en Automatique. (2006) CeCILL Free Software License Agreement. [online]. Available from: https://cecill.info/licences/Licence_CeCILL_V2-en.html [Accessed 22 July 2021].

[6] Commissariat à l'Energies Alternatives, Centre National de la Recherche Sceintifique, Institut National de la Recherche en Informatique et en Automatique. (2013) CeCILL Free Software License Agreement. [online]. Available from: https://cecill.info/licences/Licence_CeCILL_V2.1-en.html [Accessed 22 July 2021].

[7] Commission Implementing Decision (EU) 2017/863 of 18 May 2017 updating the open source software licence EUPL to further facilitate the sharing and reuse of software developed by public administrations. Official Journal of the European Union (2017/L-128/59) 19 May. Available from: https://eur-lex.europa.eu/eli/dec_impl/2017/863/oj [Accessed 22 July 2021].

[8] Communication of 21 October 2020 ‘Open Source Software Strategy 2020-2023. Think Open'. $\operatorname{COM}(2020) 7149$ final. Available from: https://ec.europa.eu/info/ sites/info/files/en_ec_open_source_strategy_2020-2023.pdf＿[Accessed 22 July 2021].

[9] Creative Commons Corporation. Creative Commons Attribution-ShareAlike v. 3.0 Unported. [online]. Available from: https://creativecommons.org/licenses/by-sa/3.0/legalcode [Accessed 22 July 2021].

[10] Directive 2001/29/EC of the European Parliament and of the Council of 22 May 2001 on the harmonisation of certain aspects of copyright and related rights in the information society. Official Journal of the European Communities (2001/L-167/10) 22 June. Available from: http://data.europa.eu/eli/dir/2001/29/oj [Accessed 22 July 2021].

[11] Directive 2009/24/EC of the European Parliament and of the Council of 23 April 2009 on the legal protection of computer programs (Codified version). Official Journal of the European Union (2009/L-111/16) 5 May. Available from: http://data.europa.eu/eli/dir/2009/24/oj [Accessed 22 July 2021].

[12] Dusollier, S. (2007) Sharing Access to Intellectual Property Through Private Ordering. Chicago-Kent Law Review, 82(3).

[13] Eclipse Foundation. Eclipse Public License - v 1.0. [online]. Available from: https://www.eclipse.org/legal/epl-v10.html [Accessed 22 July 2021].

[14] Free Software Foundation. (1991) GNU General Public License, version 2. [online]. Availabe from: https://www.gnu.org/licenses/old-licenses/gpl-2.0.html [Accessed 22 July 2021].

[15] Free Software Foundation. (1999) GNU Lesser General Public License, version 2.1. [online]. Available from: https://www.gnu.org/licenses/old-licenses/lgpl-2.1.html [Accessed 22 
July 2021].

[16] Free Software Foundation. (2007) GNU Affero General Public License.

[17] Free Software Foundation. (2007) GNU General Public Licence. [online]..

[18] Free Software Foundation. (2007) GNU Lesser General Public License. [online]. Available from: https://www.gnu.org/licenses/lgpl-3.0.en.html [Accessed 22 July 2021].

[19] Free Software Foundation. (2008) GNU Free Documentation License. Available from https://www.gnu.org/licenses/fdl-1.3.html [Accessed 22 July 2021].

[20] Free Software Foundation. (2020) Frequently Asked Questions about the GNU Licenses. [online]. Available from: https://www.gnu.org/licenses/gpl-faq.html [Accessed 22 July 2021].

[21] Free Software Foundation. (2021) Licenses. [online]. Available from: https://www.gnu.org/licenses/licenses.html.en [Accessed 22 July 2021].

[22] Gomulkiewicz, R.W. (2005) General Public License 3.0: Hacking the Free Software Movement's Constitution. Houston Law Review, 42(4).

[23] González de Alaiza Cardona, J.J. (2007) Open Source, Free Software, and Contractual Issues. Texas Intellectual Property Law Review, 15(2).

[24] Gue, Th. (2012) Triggering the Infection: Distribution and Derivative Works under the GNU General Public License. University of Illinois Journal of Law, Technology \& Policy, 1.

[25] IDABC. (2009) European Union Public Licence - EUPL v.1.1. [online]. Available from https://wayback.archive-it.org/12090/20200212153832/https://ec.europa.eu/idabc/ eupl.html [Accessed 22 July 2021].

[26] Joinup. Impact of the EUPL. [online]. Available from: https://joinup.ec.europa.eu/collection/eupl/impact-eupl [Accessed 22 July 2021].

[27] Judgment of 5 October 2009, Bezpečnostní softwarová asociace, C-393/09, EU:C:2010:816.

[28] Judgment of 2 May 2012, SAS Institute Inc., C-406/10, EU:C:2012:259.

[29] Marrakesh Agreement Establishing the World Trade Organization - Annex 1C. Agreement on Trade-Related Aspects of Intellectual Property Rights, 15 April 1994. Available from: https://www.wto.org/english/docs_e/legal_e/27-trips_01_e.htm [Accessed 22 July 2021].

[30] Morgan, M.F. (2010) the Cathedral and the Bizarre: an Examination of the "Viral" Aspects of the GPL. John Marshall Journal of Computer and Information Law, 27(3).

[31] Mozilla Foundation. Mozilla Public License Version 2.0. [online]. Available from: https://www.mozilla.org/en-US/MPL/2.0/ [Accessed 22 July 2021].

[32] Open Source Initiative. (2004) the Open Software License 2.1 (OSL-2.1). [online]. Available from: https://opensource.org/licenses/osl-2.1.php [Accessed 22 July 2021]. 
[33] Open Source Initiative. (2005) the Open Software License 3.0 (OSL-3.0). [online]. Available from: https://opensource.org/licenses/OSL-3.0 [Accessed 22 July 2021].

[34] Osborne, K. (2015) License Profile: the Eclipse Public License. International Free and Open Source Software Law Review, 7(1).

[35] Québec - Forge gourvenementale. (2019) Québec Free and Open-Source Licence version 1.0 Reciprocity. [online]. Available from: https://forge.gouv.qc.ca/licence/en/liliq-v1-0/ [Accessed 22 July 2021].

[36] Québec - Forge gourvenementale. (2019) Québec Free and Open-Source Licence version 1.1 Reciprocity. [online]. Available from: https://forge.gouv.qc.ca/licence/en/liliq-v1-1/ [Accessed 22 July 2021].

[37] Québec - Forge gourvenementale. (2019) Québec Free and Open-Source Licence version 1.0 Strong Reciprocity. [online]. Available from: https://forge.gouv.qc.ca/licence/en/liliq-v1-0 [Accessed 22 July 2021].

[38] Québec - Forge gourvenementale. (2019) Québec Free and Open-Source Licence version 1.1 Strong Reciprocity. [online]. Available from: https://forge.gouv.qc.ca/licence/en/liliq-v1-1/ [Accessed 22 July 2021].

[39] Raymond, E.S. (2000) the Cathedral and the Bazaar. [online]. Available from: http://www.catb.org/ esr/writings/cathedral-bazaar/cathedral-bazaar/ [Accessed 22 July 2021].

[40] Request of 9 May 2018, Dacom Limited v IPM Informed Portfolio Management AB, C313/18, Official Journal of the European Union (2018/C-268/31) 30 July. Available from: https:/eur-lex.europa.eu/legal-content/EN/TXT/?uri=CELEX\%3A62018CN0313 [Accessed 22 July 2021].

[41] Schmitz, P.-E. (2013) the European Union Public Licence (EUPL). International Free and Open Source Software Law Review, 5(2).

[42] Schmitz, P.-E. (2014) EUPL v.1.1. European Union Public Licence. Guides for Users and Developers. Available from: https://joinup.ec.europa.eu/collection/eupl/guidelines-usersand-developers [Accessed 22 July 2021].

[43] Schultz, C. (2005) Ziffer 0. In: Die GPL kommenirt und erklärt. Köln: O’Reilly.

[44] Unni, V.K. (2016) Fifty Years of Open Source Movement: an Analysis through the Prism of Copyright Law. Southern Illinois University Law Journal, 40(2).

[45] Villa, L. (2010) Lawyers in the Bazaar: Challenges and Opportunities for Open Source Legal Communities. International Free and Open Source Software Law Review, 2(1).

[46] Wiebe, A. and Heidinger, R. (2009) European Union Public Licence - EUPL v. 1.1. 